\title{
Educación ambiental y educación para el desarrollo sostenible ante la crisis planetaria: demandas a los procesos formativos del profesorado*
}

\author{
William Manuel Mora Penagos ${ }^{* *}$ \\ Artículo recibido: 30-05-2009 y aprobado: 12 -11-2009 \\ Environmental education and education for sustainable development: \\ demands to the formative processes of the educators
}

Resumen: Contextualizada la actual situación de crisis mundial, que destaca la variable ambiental como trasfondo de causas y consecuencias de ésta, la presente comunicación muestra las tensiones entre la Educación Ambiental y la Educación para el Desarrollo Sostenible; la necesidad de una educación ambiental crítica y pertinente, sus implicaciones en las actividades docentes y en los procesos formativos alrededor de propuestas curriculares adecuadas.

Palabras clave: Crisis ambiental, educación para la sustentabilidad, enseñanza de las ciencias, ambientalización curricular, formación docente.
Abstract: After contextualizing the current global crisis, which highlighted the environmental variable as background of causes and consequences of this issue, this paper demonstrates the tensions between the Environmental Education and Education for Sustainable Development, the need for relevant and critical environmental education, and their implications for teaching activities as well as their learning processes on relevant curricular proposals.

Key words: Environmental crisis, education for sustainability, science teaching, curriculum, teacher education.

\footnotetext{
Proyecto: 019-2006. Financiado por el Centro de Investigaciones y Desarrollo Científico - Universidad Distrital Francisco José de Caldas.

** Profesor de planta de la Universidad Distrital Francisco José de Caldas. Facultad de Medio Ambiente y Recursos Naturales.wmora@udistrital.edu.co
} 


\section{Los problemas ambientales globales como resultado de la crisis del desarrollo y del conocimiento}

Desde finales del siglo pasado ha aumentado la convicción general de estar en un periodo de la humanidad de verdadera crisis cultural y en la civilización de la modernidad tecno/desarrollista y productivista/consumista (Ángel, 1995; Caride y Meira, 2001; Leff, 2002) asociada a los procesos de globalización de la economía, del conocimiento, de la información y de la geopolítica, que han conducido a un "pensamiento único" y a una "sociedad del riesgo" (Lujan y Echeverría, 2004).

La "verdad incomoda" del cambio climático, el incremento de fenómenos de desigualdad entre norte y sur (ricos y pobres), el aumento del fundamentalismo político y religioso asociado a la carrera armamentista (especialmente nuclear y bioquímica), y las actuaciones especulativas de las grandes bolsas de valores (que han llevado al mundo a la actual crisis financiera global con desequilibrios macroeconómicos y pérdida de millones de empleos), amenazan la igualdad, la paz social y el medio ambiente, generando un problema público de miedo social al futuro, que algunos catastrofistas y apocalípticos han aprovechado para anunciar el acercamiento al punto de no retorno o de estado inevitable de extinción de la especie humana y de toda forma de vida en el planeta Tierra (Leakey y Lewin, 1997).

Para muchos, la crisis ambiental tiene como causas el hiperconsumo, la explosión y transición demográfica; las inequidades y desequilibrios humanos; la actividad de las organizaciones mafiosas; la urbanización creciente y desordenada y la actividad especuladora de empresas transnacionales. Ellos olvidan que crisis y globalización son dos caras de una misma moneda, cuya causa fundamental depende de la articulación del modelo económico desarrollista y la producción científico/tecnológica.

Este vínculo obedece a un modelo occidental basado en el poder del mercado y del desarrollo, a una exagerada confianza en que la ciencia y la tecnología sabrán cómo responder al agotamiento de los recursos y a los procesos de contaminación; en este punto de vista muchas veces no se reconoce que no es sólo la pobreza la que presiona el agotamiento de recursos y la mayor contaminación, sino que también lo es el estilo de vida opulento de las sociedades desarrolladas que consumen y contaminan en una proporción muy superior a la de los habitantes de los países más pobres que genera una mayor huella ecológica.

\section{Naturaleza de los problemas ambientales, conocimiento tecno-científico y sistemismo}

Las soluciones a la crisis global que han encontrado mayor consenso, reconocen que los problemas ambientales no son sólo problemas del desarrollo, sino básicamente, problemas del conocimiento y de la educación que van más allá del aprendizaje acerca del medio, y que además tienen que ver con la forma de entender y abordar los problemas ambientales. Para esto se requiere que el paradigma de la modernidad tecno-científica deba ser analizado, cuestionado y reconstruido (Mora, 2007), empezando por aceptar que con el paso de los siglos, la modernidad ha estimulado la separación del sujeto del objeto, en el afán de producir resultados objetivos y verdaderos; la disyunción e incomunicación 
entre las ciencias de la naturaleza y las ciencias sociales; la tendencia a separar y atomizar en partes los objetos de investigación; el desarrollo disciplinar, compartimentado y fragmentado; la pretensión de carácter anónimo del saber científico - tecnológico; la neutralidad ideológica y su tendencia a separar la reflexión filosófica de la teoría científica y tecnológica; el neo-oscurantismo que ha generado la súper especialización, donde el especialista deviene en ignorante en todo lo que no concierne a su especialidad; el aumento de la capacidad de manipulación del conocimiento científico-técnico sobre las cosas físicas y los seres vivos.

Esta concepción de las ciencias (que difícilmente permite enfrentarse a la complejidad de los problemas ambientales globales) ha sido fuertemente criticada como producto de eventos históricos vinculados con la crisis de la física clásica, cuando los conceptos de entropía y de irreversibilidad intrínseca de los fenómenos naturales determinaron un vuelco ontológico desde la termodinámica de los procesos, y que dan entrada a la indeterminación y al azar, la dualidad materia/ energía, concediendo más relevancia a las interacciones y al movimiento entre los objetos, establecidos desde la mecánica cuántica y la mecánica relativista (GarcíaDíaz, 1998).

Hoy se reconoce que el estado de crisis civilizatoria en que se encuentra el planeta Tierra, implica asumir las relaciones sociedad/naturaleza desde una concepción de "complejidad ambiental" (de hibridaciones epistemológicas y ontológicas) sobre la comprensión del mundo y del ser (Leff, 2002; García Díaz, 2004), que requieren esencialmente de una visión sistémica, compleja, crítica, constructivista y hermenéutica para su comprensión.

Bajo criterios sistémicos y complejos se ha reclamado la integración epistemológica entre las ciencias naturales, las ciencias sociales y otros tipos de conocimientos (ancestrales, religiosos, populares, etc.) en un "diálogo de saberes" que permita una formación para la comprensión y participación en la solución de este tipo de problemas, todos ellos de naturaleza compleja (que se dan en relación dialéctica entre los sistemas cultural/ecosistema, simbólico/ biótico) en un contexto planetario en emergencia que requiere que todos nos involucremos en salvar la nave espacial (Tierra - Patria, como diría Edgar Morín) en que viajamos.

Más que un campo interdisciplinar en donde los saberes populares se hacen fundamentales (para lo que se requiere superar su subvaloración como una dimensión cultural de menor valor), este dialogo de saberes requiere también de un conocimiento tecnológico que supere su papel subordinado a las ciencias (como ciencia aplicada) que le ha generado un estatus de inferioridad que supedita todo aspecto práctico a lo teórico y que ha afectado la necesidad de su reflexión epistemológica (López Cerezo y Luján, 1998).

Los problemas ambientales no pueden ser estudiados por simple adición de investigaciones disciplinarias, pues son originados por la interrelación de sistemas complejos adaptativos (propio de lo vivo, de los sistemas abiertos alejados del equilibrio) como las dinámicas de los ecosistemas y la evolución de las sociedades humanas, en las que cada uno de estos sistemas procesa información, aprendiendo acerca de su entorno 
y de la interacción entre sí, identificando regularidades, condensándola en una especie de modelo (donde la complejidad depende de la heterogeneidad, interdefinibilidad y mutua dependencia de las funciones que cumplen los elementos dentro del sistema y su gradiente de complejidad que depende del tamaño del esquema para generar las interrelaciones) y actuando en el mundo real sobre la base de dicho esquema por competencia con otros esquemas, y los resultados de la acción influyendo de modo retroactivo; situándose en una zona de transición bien definida entre el orden y el desorden en una adaptación eficiente (Gell-Mann, 2003; García, 2006).

En razón a la heterogeneidad de los elementos del sistema y de sus distintas interacciones y emergencias, se hace necesario abordar los problemas ambientales a partir de criterios de inter $y$ transdisciplinariedad, así, García (2006) dice que llamará "investigación interdisciplinaria al tipo de estudio que requiere un sistema complejo" y que "lo que integra a un equipo interdisciplinario para el estudio de un sistema complejo es un marco conceptual y metodológico común, derivado de una concepción compartida de la relación ciencia - sociedad, que permitirá definir la problemática a estudiar bajo un mismo enfoque, resultado de la especialización de cada uno de los miembros del equipo de investigación".

En esta actividad la interdisciplinariedad depende de la existencia de las especializaciones disciplinares, por lo que se oscila entre dos extremos radicales, la especialización absoluta y la generalidad excesiva, diferenciación/integración que tienen lugar en el proceso que conduce a la definición y estudio de un sistema complejo en el diagnóstico de sus raíces, bien sea para prevenirlos, para generar políticas que detengan o reviertan el deterioro encontrado.

La naturaleza compleja de la problemática ambiental reclama un nuevo modelo de pensamiento, propio de una visión sistémica, en donde a la acción de separar, propia de la modernidad y de la super especialización tecno-científica, complemente la acción de unir, combinar, conectar e interaccionar. Ciencia y tecnología, siendo por un lado, propias de la modernidad y por otro, sistémicas. Aunque son dos formas de conocer opuestas, se apoyan antes que excluirse, pues más que buscar una oposición o cambio de paradigma con la modernidad, la sistémica pretende un estado de síntesis con ella, que parte de la crítica de la razón, la objetividad, el individualismo y la disciplinariedad, combinándose con miradas holísticas e interculturales en la emergencia de una "cultura planetaria" que integra y concilia tradiciones en una tensión de opuestos: racionalidad/intuición, cantidad/calidad, análisis/síntesis, reduccionismo/holismo, pensamiento lineal/pensamiento sistémico, competición/cooperación, determinismo/indeterminismo, orden/ desorden, estado/ proceso ciencia/tecnología, ambiente/ cultura (García-Díaz, 2000, 2004).

Es un pensamiento complejo que se presenta como un método (Morín, 2000), que no resuelve en sí mismo los problemas, pero que se constituye en ayuda para el diseño de estrategias de soluciones, siendo los principios dialógico, hologramático, y de recursividad de gran potencial educativo (Morín, 2001). Epistemología compleja, que, como diría Garciandía (2005), articula cibernética (causalidad circular) con constructivismo (concepción de la realidad), hermenéuti- 
ca (lenguaje y arte de la interpretación) y complejidad (método de pensar sistémico), y adicionalmente ética y estética, entre otros aspectos que tendrían que ser tratados en los currículos ambientales dentro de las especificaciones propias de cada cultura.

\section{Soluciones alternativas al desarrollismo}

Para algunos expertos la solución a la crisis global no está en reactivar el crecimiento económico fundamentado en el consumismo (y sus tres ingredientes: la publicidad que crea la necesidad de consumir; el crédito fácil que otorgado por las entidades financieras; y la obsolescencia acelerada y programada de los productos) bajo criterios del desarrollo sostenible (bien sea propuesto por el capitalismo neoliberal o el socialismo productivista), sino en aprovechar el momento histórico para introducir alternativas al desarrollismo económico.

Estas alternativas no son nuevas, sino que son consecuencia del informe del Club de Roma de 1972 (Los límites del crecimiento) en el que se afirmaba que, en un planeta limitado, las dinámicas de crecimiento exponencial (no sólo del PIB, sino también de la población) no son sostenibles y que se debería detener el crecimiento, generando un estado estacionario de equilibrio dinámico (teoría del "crecimiento cero"), fundamentado en la constatación de la imposibilidad termodinámica de una economía en crecimiento continuo, como lo dieron a conocer bio-economistas destacados como Herman Daly.

Una variante radical de la idea de crecimiento cero, es la de decrecimiento, que aunque tiene puntos comunes (desde hace más de treinta años), como el surgir de la toma de conciencia de la crisis ecológica y la crítica a la tecnología y al desarrollo; se diferencia éste en tanto que mientras el crecimiento cero trata de un decrecimiento forzado dentro del mismo sistema imperante, el decrecimiento persigue una opción civilizadora alterna al desarrollismo (como se evidencia en la "declaración de la conferencia internacional "decrecimiento para la sostenibilidad ecológica y la equidad social”, celebrada en París en abril de 2008), que implica la deconstrucción de la economía, al tiempo que construye una nueva racionalidad productiva (Leff, 2008), argumentada en que ya no basta con echar el freno al móvil; hay que poner la marcha atrás para evitar el abismo (Fundació Terra, 2008); sin embargo, tanto el concepto de "crecimiento cero" como el "decrecimiento económico" se han enfrentado a desafíos semejantes: crítica utópica, crecimiento moral y un debate sobre los "fines últimos" (Kerschner, 2008).

Los teóricos del decrecimiento no sólo vinculan la bio-economía, inspirada en las tesis del rumano GeoergescuRoegen, a la crítica de la teoría económica estándar, sino que también se fundamentan en el ecologismo social o socio-político e incluso en proyectos distintos del socialismo tan diversos como el cristiano (preocupado por el consumo, especialmente en que todos tengan sus necesidades básicas cubiertas, pero despreocupado por las formas de producción de esos bienes), postulando que el decrecimiento tendría que organizarse no sólo para preservar el medio ambiente, sino para restaurar un mínimo de justicia social. Por otra parte, los seguidores del acrecimiento distinguen entre decrecimiento "soste- 
nible" e "insostenible" o caótico, siendo un ejemplo de ello el que tuvo lugar en Rusia desde 1990 (como consecuencia de la desindustrialización no buscada o deseada), y por otro lado el decrecimiento "sostenible", que se correlaciona con una "economía sana" (Fernández Buey, 2007), sustentada en la democracia y el humanismo".

En general el decrecimiento agrupa esencialmente un conjunto de propuestas humanistas, pero también de "ecología profunda" para reducir nuestro crecimiento económico y sustituirlo por otra noción y otra cultura en la búsqueda de la felicidad y el bienestar, con ello plantea el abandono de la fe en la economía del crecimiento, el progreso y el desarrollo permanente, mostrándose muy crítico de la noción de Desarrollo Sostenible, planteada en el Informe Brundtland de las Naciones Unidas en 1987, (que persigue el crecimiento económico ecológicamente sostenible), que como se ha observado durante los últimos años ni siquiera es respetada, como se evidencia en la aplicación de los acuerdos de Kyoto que ha estado plagado de obstáculos y zancadillas por parte de los mismos gobiernos que decían defender la idea de desarrollo sostenible. Nicolás Ridoux (2009) (citando a Niklos Persanyi) nos dice que crecimiento $y$ sostenibilidad están yuxtapuestos mediante la siguiente situación: "cuando vuestro cuarto de baño se inunda, ¿os contentáis con recoger el agua del suelo? Personalmente, yo empiezo por cerrar el grifo". Recoger el agua es el desarrollo sostenible, cerrar el grifo es decrecimiento sostenible.

Eficiencia, coherencia y suficiencia se han convertido en principios del decrecimiento. La eficiencia, pone en evidencia el "efecto rebote" al que nos conduce el desarrollo sostenible, es decir que el ahorro logrado inicialmente en materias primas y energía, queda desperdiciado por el consumo cuantitativamente mayor que fue provocado por tal mejora (como ocurre con la fabricación de los automóviles cada vez más ahorradores en el gasto de combustible, pero cada vez más obsoletos en sus partes en poco tiempo, lo que aumenta el consumo y por ende el gasto energético).

La coherencia, que es lo que Jorge Riechmann (2006) denomina "biomímesis" o ecoefectividad que, imitando la economía cíclica natural de los ecosistemas, articula economía verde y desarrollo humano en torno a conductas eficientes y renovables a nivel energético y alimentario como camino para disminuir nuestra huella ecológica y reanimar la economía global (contrario a ello, el discurso empresarial y gubernamental de la sostenibilidad sólo apunta a mejorar la gestión y saneamiento ambiental de la planta física, sin hacer mucho por la cultura ambiental de su personal que se caracteriza por el consumismo exacerbado y de permanente insatisfacción). Linz, Riechmann, y Sempere, (2007), en el libro "Vivir (bien) con menos" proponen reflexionar sobre el tercer camino, la suficiencia o austeridad (inoportuno personaje que de pronto se presenta críticamente a quienes pretenden concertar capitalismo y medio ambiente), que propone escoger entre organizar la producción y el consumo de otra manera (desde la mesura y la suficiencia y no desde el "siempre más") o continuar acercándonos al abismo ecosida.

Líderes del decrecimiento como Serge Latouche (2009) reconocen que el término decrecimiento no es el más apropiado 
y que es más exacto hablar de "acrecimiento" (identificado con la expresión en inglés, decreasing growth o crecimiento decreciente) que no implica el decrecimiento de todo, sino que se orienta hacia la disminución del consumo de materia y energía, principalmente el producto interior bruto (Fernández Buey, 2007), desplazando los acentos hacia los "bienes relacionales” (atenciones, cuidados, conocimientos, participación, nuevos espacios de libertad y de espiritualidad, etc.) y hacia una economía solidaria.

Todo eso implica, obviamente, un cambio radical en la forma de producir, de consumir y de vivir, una nueva forma económica y social de organizarnos para avanzar hacia un mundo sustentable, que requiere un profundo reequilibrio cuya consecuencia sería el crecimiento de algunas zonas del planeta y el decrecimiento de otras, así, el decrecimiento aparece como una necesidad y no como sólo un ideal, sobre todo porque en principio, la palabra misma no debería funcionar como un simple cliché negativo del crecimiento, por el contrario, debería ser un estimulo para construir sociedades convivenciales que ahorren y sean autónomas. Si en el norte el decrecimiento es claramente la reducción de los niveles de consumo, en el sur es el intento de un desarrollo que, eliminando los obstáculos que impiden que las sociedades avancen, desemboque en un decrecimiento sereno, convivencial y sostenible, como diría Latouche (2009).

Serge Latouche (2009) -profesor emérito de Economía de la Universidad París -Sud XI (Orsay) - propone lo que llama el "círculo virtuoso del decrecimiento sereno", una revolución que implique transformar la sociedad a partir de las llamadas ocho "R", sobre las que se soportan las bases de lo que debemos hacer:

1. Revalorizar: cambiar de valores, altruismo en vez de egoísmo, cooperación en lugar de competencia, ocio por encima del trabajo, vida social por encima del individualismo, etc.

2. Reconceptualización: replantearse lo que significa riqueza y pobreza

3. Reestructuración: todo el sistema productivo tiene que transformarse, adaptando las estructuras económicas y productivas al cambio de valores.

4. Redistribución: entre las clases, entre los pueblos, entre los individuos, dando acceso a los recursos naturales y las riquezas

5. Relocacionar: dar primacía a lo local, que permite controlar y decidir directamente.

6. Reducir: el sobreconsumo, los residuos, las horas de trabajo, los riesgos sanitarios, el transporte, limitando el consumo a la capacidad de carga de la biosfera.

7. Reutilizar: tender hacia bienes durables y a su reparación y conservación.

8. Reciclar: en todas nuestras actividades facilitándolo al máximo a los ciudadanos.

Por su parte Georgescu-Roegen propone su fórmula de nueve puntos que permitirán poner en marcha los círculos virtuosos del acrecimiento:

1. Volver a los años sesenta-setenta para la producción material, con una huella ecológica igual o inferior a un planeta.

2. Internalizar los costes del transporte y evitar los viajes kilométricos de todas las mercancías.

3. Relocalizar las actividades para que la producción se sitúe cerca del consumidor.

4. Adoptar el programa de la agricultura cercana a la población.

5. Impulsar la producción de bienes relacionales. 
6. Adoptar el escenario Megawatt y el del Factor 4 para reducir el derroche de energía.

7. Penalizar fuertemente los gastos publicitarios.

8. Decretar una moratoria sobre la innovación tecnológica para hacer un balance serio y reorientar la investigación científica y técnica en función de las nuevas aspiraciones.

9. Adoptar un estilo de vida más frugal, que reduzca nuestra adicción al consumo.

En declaración de la conferencia internacional "Decrecimiento para la sostenibilidad ecológica y la equidad social" de 2008, quedó redactado que el proceso de decrecimiento se caracteriza por seis pilares:

1. Énfasis en la calidad de la vida por encima de la cantidad del consumo.

2. La satisfacción de las necesidades humanas básicas para todo el mundo.

3. Un cambio social basado en acciones y políticas individuales y colectivas.

4. Una reducción sustancial de la dependencia de actividades económicas y un incremento del tiempo libre, de las actividades no remuneradas, de la convivencialidad, del sentido comunitario y de la salud individual y colectiva.

5. El estímulo de la auto-reflexión, del equilibrio, de la creatividad, de la flexibilidad, de la diversidad, de la responsabilidad ciudadana, de la generosidad, del nomaterialismo.

6. Respeto de los principios de equidad, democracia participativa, derechos humanos y de las diferencias culturales.

Sin duda, uno de los principales problemas que enfrenta nuestra civilización, es que nos hemos convertido en analfabetos energéticos, por eso, recuperar la educación energética es esencial para avanzar hacia una sociedad duradera y se convierte en un campo estratégico de la educación ambiental. Desconocer los datos del consumo eléctrico en nuestra casa y las consecuencias ambientales, es solo la punta del iceberg, se requiere del estudio de las fuentes energéticas fósiles y su agotamiento, su comparación con el aporte de las energías renovables y la proporción en que incorporan problemas ambientales, todo para evaluar el riesgo ecológico que asumimos. Las energías renovables nos obligan a un estilo de vida más eficiente, más ahorrador y, sobre todo, más consciente de aquello que supone la energía.

También han aparecido propuestas, como la del "crecimiento controlado", descrita por el socioantropólogo y filósofo Edgar Morín (2008:18), quien dice que "la respuesta no estaría en una solución milagrosa, en el crecimiento cero del estado estacionario, sino en el crecimiento controlado" atendiendo a las necesidades del desarrollo humano y no sólo de las necesidades industrializadas de la nave Tierra-patria en que viajamos (propulsada por cuatro motores: la ciencia, la técnica, la industria y la economía de mercado; la cual carece de piloto y en la que los pasajeros riñen entre sí todo el tiempo).

Morín (2008:86) sostiene que la condición planetaria “... que ha provocado y provoca el desarrollo ha tratado de regularlo con la noción de desarrollo sostenible" bajo la forma edulcorada de sustentable, debe ser criticada porque sostiene un núcleo ciego tecno-económico, que cree que todo progreso humano emana del crecimiento material y que su aplicación, en todo el mundo, no ha conducido sino a destruir solidaridades tradicionales, desencadenando la corrupción y el egocentrismo.

Morín (2008:106, 138) propone transformar la noción de desarrollo bajo 
una "política de humanidad" (que comportaría la instauración de regulación y control económico en una instancia de representación del conjunto de las naciones) y una "política de civilización" (simbiosis entre lo mejor que tiene la civilización occidental y las aportaciones extraordinariamente ricas de las demás civilizaciones) que llevarían a remplazar el concepto de globalización por el de "sociedad mundo" bajo la "senda de la esperanza" y sus tres principios: lo improbable pero posible, el de las potencialidades humanas todavía no actualizadas, generadoras y regeneradoras, y el de "posibilidad de metamorfosis", que pueda contribuir a enfrentar el estado de crisis y caos en que nos encontramos.

Habrá que reconocer también otras fórmulas alternativas que han surgido alrededor de estos temas; desde el movimiento ecologista (que defiende la necesidad de una cultura de la suficiencia con un contenido más integrador); el movimiento feminista (que defiende la búsqueda de una nueva relación entre el cuidado de la vida y el de la naturaleza); los pueblos indígenas (que nos reclaman el acercamiento a conocimientos ancestrales y reivindican el ideal del 'Buen Vivir' entre los seres humanos y la Tierra) (Bosch, Carrasco y Grau: 2005. Citado por Pastor, 2009); la "espiritualidad científica" de aquellos autores que se han implicado en el estudio de la física cuántica (como se expresa en el film What the bleep do we know [" ¿Y tú qué sabes?"]).

En esta última tendencia se inscribe Ervin Lazlo (2009), quien afirma que frente al estado de bifurcación y crisis social en que se encuentra nuestro planeta estamos ante la disyuntiva de evolucionar hacia una civilización soste- nible o descender a la violencia, el caos y la posible extinción; Lazlo propone una modalidad que puede ser una alternativa eficaz frente al crecimiento extensivo, el crecimiento intensivo. Sus metas de conexión, comunicación y consciencia, podrían permitir el cambio, de una civilización basada en el logos, hambrienta de poder y conquista, a una civilización de holos, centrada en el crecimiento de los individuos y en la sostenibilidad de las comunidades humanas y la biosfera. Esta civilización del holos se centra en la ética ecológica y planetaria, se orienta en la formación de un estilo de vida definido por la simplicidad voluntaria y la búsqueda de una nueva moralidad, de una armonía con la naturaleza entendiéndola como pleno cósmico o medio que conecta todas las cosas a través de un espacio sin vacío, articulado con el tiempo y que crea el tipo de coherencia manifiesta entre ellas.

Sin embargo hay que decir que las propuestas de mayor influencia internacional en este momento, no parecen estar en la línea de las anteriores alternativas aunque lo parezcan. La Carta de la Tierra, promulgada durante la cumbre de Rio de Janeiro en 1992, asume un compromiso con el desarrollo sostenible en términos que sean compatibles con los recursos de que disponemos (limitados, finitos y mal repartidos) y con la conservación del medio ambiente.

Establece como objetivo fundamental restaurar y proteger la Tierra como hogar seguro no solo para la humanidad sino para toda la comunidad viviente; para ello se dirigió a las distintas culturas, religiones y grupos humanos, haciendo un llamando a la interdependencia global y responsabilidad universal, a la alianza entre gobiernos, sociedad civil 
y empresas como mecanismo para la gobernabilidad efectiva. El principio de este llamado es ver la conveniencia de integrar las dimensiones ético-social, científica y económica, como bases para generar acciones hacia el respeto y cuidado de la comunidad de la vida; la integración ecológica; la justicia social y económica; la democracia; la no violencia y la paz (Novo, 2003). El Desarrollo Sostenible (DS) tiene un ostensible atractivo al integrar dos nociones en tensión: por un lado, la necesidad de promover la conservación o preservación de la naturaleza no-humana y por la otra, permitir las aspiraciones humanas de "desarrollo", con sentido de "eficiencia" (Le Grange, 2008).

Sin embargo Lucié Sauvé (2007) nos previene diciendo que la propuesta del desarrollo sostenible presenta una determinada inclinación cultural que se traduce en una cosmología norteoccidental dualista (naturaleza/serhumano, sociedad/medio ambiente) que no existe en otras culturas. Visión del mundo ilustrada por tres círculos distintos pero interpenetrados: economía, sociedad y medio ambiente. La economía (cuyo crecimiento es necesario estimular) es concebida como una entidad autónoma, teniendo su existencia y su dinámica propia fuera de la sociedad; el medio ambiente circunscrito a un conjunto de recursos que es necesario utilizar de manera "racional" para no agotar las "existencias" y "servicios", lo que perjudicaría a la durabilidad de la actividad económica; y la sociedad, que se reduce a una función de producción y consumo, convirtiendo en capital para el desarrollo lo humano entendido como capital humano y capital social.
Mas recientemente, los "teóricos" del desarrollo sostenible se dieron cuenta de un "olvido"... ellos entonces añadieron el círculo de la cultura, como un contexto de fondo que hay que tener en cuenta para establecer mejor el desarrollo sostenible. Sauvé (2007) cita a otros autores, que consideran el DS como un giro de "cambio de paradigma", un oximorón (que armoniza dos conceptos opuestos en una sola expresión: ej. capitalismo global y sustentabilidad, o como lo pueden ser las frases: guerras limpias, el consumismo verde, o la economía solidaria), un fetiche, una cortina de humo, una consigna política o un eslogan para mantener una reforma sin cambios, donde lo que finalmente prevalece y de manera abrumadora es lo económico.

\section{Tensión entre Educación Ambiental (EA) y Educación para el Desarrollo Sostenible (EDS)}

Como derivado de la Carta de la Tierra (en Río 1992), la década 1997 2007, ha visto surgir la EDS, que según Naciones Unidas (2005), es un proceso educativo para lograr el desarrollo humano (crecimiento económico, desarrollo social y la protección del medio ambiente) de una manera incluyente, equitativa y segura, para lo cual integra diez campos emergentes (con los que todos podríamos estar de acuerdo): reducción de la pobreza, equidad de género, promoción de la salud, conservación y protección ambiental, transformación rural, derechos humanos, entendimiento intercultural y paz, producción y consumo responsable, diversidad cultural, tecnologías de la información y la comunicación.

Naciones Unidas ha planteado la " $D e ́$ cada de la Educación para el Desarrollo Sostenible (2005-2014)" (DEDS), -de cuya 
promoción es responsable la UNESCO-, defendiendo un entramado de medidas tecnológicas, políticas y educativas, como respuesta al hecho de que gran parte de la ciudadanía y sus representantes políticos no han hecho eco de la necesidad de integrar la perspectiva del desarrollo sostenible a todos los niveles de la sociedad; estas medidas buscan convertir la educación en un agente para el cambio, que requiere para tal propósito implicar a todos los sectores, desde los responsables ministeriales y de las universidades, hasta los profesores y estudiantes, impulsando a la vez medidas oficiales (de cambios curriculares, promoción de cursos para la formación docente desde los centros de profesores, las consejerías, las universidades, etc.).
En este contexto la EDS es presentada como una alternativa optimista, progresista, exitosa y deseable frente a una EA juzgada como reduccionista, anacrónica e ineficaz frente a los retos de la globalización económica y de la irrupción de la "sociedad del conocimiento", por lo que resulta necesario permear con ella los medios masivos de comunicación, la familia, los negocios y la fuerza de trabajo (Irwin, 2008). Los defensores de la EDS ven en esta alternativa una respuesta integral acorde con nuestro tiempo, capaz de superar las deficiencias y sesgos de la EA, como se puede ver en la siguiente tabla comparativa propuesta por Goncz y otros (Lukman y Glavic, 2007).

\begin{tabular}{|c|c|}
\hline Educación Ambiental (EA) & Educación para el Desarrollo Sostenible (EDS) \\
\hline $\begin{array}{l}\text { Se ocupa de los problemas } \\
\text { ambientales. }\end{array}$ & $\begin{array}{l}\text { Trata de una manera integrada la protección del medio ambiente, el uso } \\
\text { eficaz de los recursos naturales, el mantenimiento del ecosistema, una } \\
\text { sociedad que funcione bien y una economía sólida. }\end{array}$ \\
\hline $\begin{array}{l}\text { Los problemas ambientales } \\
\text { dependen de las actividades } \\
\text { humanas y sus efectos sobre el } \\
\text { medio ambiente. }\end{array}$ & $\begin{array}{l}\text { El problema parte de un conflicto entre los diferentes objetivos } \\
\text { humanos: ambientales, económicos, sociales y culturales (dualidad). }\end{array}$ \\
\hline Se centra en la biodiversidad. & Se concentra en la diversidad cultural, social, económica y biológica. \\
\hline $\begin{array}{l}\text { El objetivo de la acción: un } \\
\text { buen ambiente. }\end{array}$ & Una buena calidad de vida en el presente y para las generaciones futuras. \\
\hline $\begin{array}{l}\text { Acciones para el medio } \\
\text { ambiente. }\end{array}$ & $\begin{array}{l}\text { Motivación para el cambio en el estilo de vida, basada en cuestiones } \\
\text { importantes de la existencia personal. }\end{array}$ \\
\hline $\begin{array}{l}\text { La responsabilidad por el } \\
\text { medio ambiente. }\end{array}$ & $\begin{array}{l}\text { La responsabilidad para el desarrollo humano y el destino de los } \\
\text { ecosistemas, de los cuales los seres humanos son parte. }\end{array}$ \\
\hline $\begin{array}{l}\text { El comportamiento individual } \\
\text { (la ética del medio ambiente). }\end{array}$ & $\begin{array}{l}\text { Aumenta la competencia de acción, incluida la capacidad para } \\
\text { desarrollar criterios morales, y estimula la participación pública en la } \\
\text { toma de decisiones. }\end{array}$ \\
\hline $\begin{array}{l}\text { La educación ambiental tiene } \\
\text { un contexto local y global. }\end{array}$ & $\begin{array}{l}\text { La EDS deberá basarse y aplicarse en el contexto económico, social, } \\
\text { cultural y ecológico local, pero seguido de los contextos regionales, } \\
\text { nacionales y mundiales. }\end{array}$ \\
\hline Impartido en algún tema. & $\begin{array}{l}\text { Integrada en toda la enseñanza y el aprendizaje en los distintos niveles } \\
\text { del proceso de educación y desarrollo personal (formal, no formal, } \\
\text { informal, permanente, la vida amplia y continua). }\end{array}$ \\
\hline
\end{tabular}

Tabla 1. Comparación entre EA y EDS. 
Autores como González-Gaudiano (2006,2008), Sauvé (2007), Irwin (2008), Meira (2008) y Caride (2008), consideran que esta relación conflictiva entre EA y EDS se ha originado después de la Cumbre de Río (1992), pero sobre todo a partir de la Conferencia de Tesalónica (1997), donde los promotores de sus declaraciones han intentado el remplazo o defunción de la EA, en favor de una EDS que sigue la lógica dominante del neoliberalismo enfocada hacia el libre mercado económico, con vínculos estrechos entre la calidad ambiental, lo socioeconómico y tangencialmente con lo ecológico; y que guiados por una racionalidad tecnocrática y metas conductistas ha ignorando asuntos como el cambio social, la equidad y la justicia.

Estos autores coinciden en que la EDS puede estar contribuyendo a la fragmentación y desconexión de los diferentes enfoques pedagógicos, donde lo ambiental se ha reducido a su mínima expresión al considerar que la crisis ambiental es más social que de índole ecológica; así la EDS se presenta con pretensiones de estadio superior de la evolución del campo de la EA, desconociendo una evolución de más de tres décadas de posicionamiento -no sin problemas- de la EA, tanto en las políticas de gestión ambiental como en la gestión educativa, tiempo en el que se ha dado como un campo en permanente construcción y lucha de configuración discursiva abierta, múltiple y relacional, pero que al tiempo, ha podido dar cuenta de un imaginario pedagógico y de un ideario político que se encuentran vigentes.

Existen fuertes críticas a la inclusión de las ideas de sostenibilidad en el programa de la Década, pues las ven como un esquema de pensamiento estrecho y pobre si se pretende aspirar a un proyecto educativo y de sociedad, pues se cree que se dedican al aprendizaje de conocimientos técnicos útiles, antes que a hablar de educación (Sauvé, 2006) al momento de intentar incluir en un mismo concepto la educación global, la educación económica, la educación para el desarrollo, la educación multicultural, la educación para la conservación, la educación al aire libre, la educación intercultural, la educación para la igualdad de sexos, la educación para el consumo, la salud y la paz, a la vez que componentes de disciplinas tradicionales como la educación cívica, la ciencia, la geografía, entre otras" (Leal, 2009).

De la misma forma en que la noción de EA puede interpretarse en varios sentidos (como "educación acerca, en y para el ambiente”), el eslogan de la EDS puede ser interpretado como promotor de cualquier desarrollo, ecológico, social o económico sustentables. La interpretación que probablemente domine es la que sea más coherente con los intereses dominantes en el contexto de instrumentación, en el caso de la EA, ésta es la "educación acerca del ambiente" y, en el caso de la EDS, es el desarrollo económicamente sustentable. Se corre el riesgo de que la EDS no implique un mejoramiento de la educación relativa al ambiente y sea un simple eslogan, en el que la enseñanza acerca del ambiente no pase de una lección de hipocresía en la que es suficiente informarse sobre la degradación ambiental sin tener que hacer algo al respecto (Le Grange, 2008). No sería aventurado anticipar que a la EDS le podría ocurrir algo semejante a lo que ha sucedido con la EA, donde la 
UNESCO, responsable de su proposición (con el Programa Internacional de EAPIEA: 1975-1995) también ha intentado su sustitución con la EDS (Capítulo 36 de la Agenda 21 - Río 1992) (Robottom, 2008).

Meira (2008) sostiene que no ha encontrado razones de carácter lógico, epistemológico, teórico-pedagógico, metodológico o ideológico para aceptar sin más que la EDS sea o pueda llegar a ser algo sustancialmente distinto, superior o más eficaz que la EA. Por su parte Lucié Sauvé (2007), en su artículo “L'équivoque du développement durable" considera que la propuesta de la EDS resulta un equívoco, un error sin precedentes, que confunde un programa políticoeconómico y un proyecto de sociedad (incluso un proyecto de civilización), con un proyecto educativo a escala planetaria, al mostrar el concepto de desarrollo sostenible como un proyecto salvador, una boya en el centro de la crisis de la seguridad que caracteriza nuestras sociedades, pero que confunde medio, sentido y finalidad.

Según Sauvé (2007) la DEDS 20052014, de las Naciones Unidas, es una manifestación y un motor de la globalización que se inscribe en el "Nuevo orden educativo mundial” de concepción neoliberal y utilitarista, que ha estimulado de forma acrítica las operaciones de reforma de todos los sistemas educativos del mundo; destinándolos a reorientar los currículos hacia la promoción del desarrollo económico sostenible y, bajo el loable objetivo de "mejorar la calidad de vida" de las generaciones actuales y futuras, ha adoptando una postura instrumental de la educación y estimulado una especie de EA light, como herramienta al servicio del programa político-económico mundial de desarrollo sostenible.

Sauvé, Berryman y Brunelle (2008), como resultado del análisis a los principales documentos internacionales promovidos por la ONU, desde la Conferencia de las Naciones Unidas sobre el medio Ambiente Humano, celebrada en Estocolmo en 1972, pasando por la Conferencia de las Naciones Unidas sobre el medio Ambiente y Desarrollo llevada a cabo en Rio de Janeiro en 1992, hasta el informe de las Naciones Unidas sobre la Educación para el Desarrollo Sostenible en el Decenio 2005-2014, muestran que si bien es posible reconocer la importancia de la participación de los órganos de la ONU para promover un desarrollo mundial responsable, (y que los documentos de la UNESCO parecen abordar una visión de la educación menos instrumental y una concepción del desarrollo más abierta a otras dimensiones y no sólo al crecimiento económico), la evaluación crítica realizada demuestra que los documentos formales de la ONU promueven las macro-tendencias socioculturales que caracterizan nuestra civilización occidental contemporánea, siendo tres los principales resultados acerca de la educación, el medio ambiente y el desarrollo: 1) la educación se concibe como un instrumento que apoya una agenda política y económica; 2) el medio ambiente es visto como un problema de recursos, y 3) el desarrollo está principalmente asociado con el crecimiento económico sostenido.

Los mismos autores muestran estos resultados en forma sintética en las siguientes tablas: 


\begin{tabular}{|c|c|}
\hline \multicolumn{2}{|r|}{ Educación } \\
\hline $\begin{array}{l}\text { Las propuestas internacionales } \\
\text { destacan, en general, los siguientes } \\
\text { aspectos: }\end{array}$ & $\begin{array}{l}\text { Las propuestas internacionales omiten, en general, los siguientes } \\
\text { aspectos: }\end{array}$ \\
\hline La educación es un instrumento. & La educación es un proceso hacia el desarrollo humano. \\
\hline $\begin{array}{l}\text { La educación es un llamado a la } \\
\text { acción para resolver problemas } \\
\text { concretos de la vida. }\end{array}$ & $\begin{array}{l}\text { La educación es un llamado a reflexionar sobre las realidades, } \\
\text { incluyendo una reflexión sobre la acción. }\end{array}$ \\
\hline Es necesario adherirse a un consenso. & $\begin{array}{l}\text { El pensamiento crítico (sin los límites de un marco } \\
\text { predeterminado) es de gran importancia. }\end{array}$ \\
\hline $\begin{array}{l}\text { El sistema educativo debe ser } \\
\text { reformado por completo; las } \\
\text { recomendaciones hechas por las } \\
\text { autoridades internacionales pueden } \\
\text { contribuir poderosamente a la } \\
\text { renovación del sistema educativo. }\end{array}$ & $\begin{array}{l}\text { Deberíamos construir sobre las lecciones del pasado y así } \\
\text { reconocer, preservar y promover las experiencias y las iniciativas } \\
\text { educativas pertinentes. }\end{array}$ \\
\hline La educación es aprendizaje. & La educación es un compromiso crítico. \\
\hline $\begin{array}{l}\text { El aprendizaje más importante es el } \\
\text { conocimiento científico y tecnológico. }\end{array}$ & $\begin{array}{l}\text { Un diálogo entre distintos tipos de conocimientos es necesario } \\
\text { para comprender completamente las necesidades socio- } \\
\text { ecológicas. }\end{array}$ \\
\hline
\end{tabular}

\section{Medio Ambiente}

\begin{tabular}{|c|c|}
\hline $\begin{array}{l}\text { Las propuestas internacionales } \\
\text { destacan, en general, los siguientes } \\
\text { aspectos: }\end{array}$ & $\begin{array}{l}\text { Las propuestas internacionales omiten, en general, los siguientes } \\
\text { aspectos: }\end{array}$ \\
\hline $\begin{array}{l}\text { Una definición general y amplia del } \\
\text { medio ambiente total. }\end{array}$ & $\begin{array}{l}\text { Una definición contextual, culturalmente significativa y } \\
\text { operacional. }\end{array}$ \\
\hline $\begin{array}{l}\text { El medio ambiente es una reserva de } \\
\text { recursos por explotar. Corresponde } \\
\text { a un conjunto de problemas por } \\
\text { resolver. }\end{array}$ & $\begin{array}{l}\text { El medio ambiente tiene un valor intrínseco; debería ser } \\
\text { comprendido a través de sus numerosas dimensiones, como } \\
\text { la naturaleza, una casa de vida compartida o un proyecto } \\
\text { comunitario. }\end{array}$ \\
\hline $\begin{array}{l}\text { Debemos actuar sobre el medio } \\
\text { ambiente. Es necesario cuestionar el } \\
\text { medio ambiente. }\end{array}$ & $\begin{array}{l}\text { Es necesario reflexionar sobre el medio ambiente y nuestras } \\
\text { relaciones con él. Es necesario "gestionar" nuestros usos del } \\
\text { medio ambiente. }\end{array}$ \\
\hline $\begin{array}{l}\text { La estrategia principal es el ahorro de } \\
\text { lo que respecta al medio ambiente: de } \\
\text { la naturaleza al capital. }\end{array}$ & $\begin{array}{l}\text { El proceso principal debería ser la ecologización de la economía: } \\
\text { del capital a la naturaleza. }\end{array}$ \\
\hline $\begin{array}{l}\text { El antropocentrismo es una postura } \\
\text { ética legítima: la biosfera está } \\
\text { destinada a servir a los seres humanos. }\end{array}$ & $\begin{array}{l}\text { Las distintas posturas éticas (como el ecocentrismo y el } \\
\text { biocentrismo) merecen ser explotadas. }\end{array}$ \\
\hline $\begin{array}{l}\text { El foco se da alrededor de las } \\
\text { relaciones entre sociedad, medio } \\
\text { ambiente y economía, para el } \\
\text { desarrollo. }\end{array}$ & $\begin{array}{l}\text { Las múltiples dimensiones de la relación humano-medio } \\
\text { ambiente deben ser consideradas. }\end{array}$ \\
\hline $\begin{array}{l}\text { El medio ambiente es indisociable del } \\
\text { desarrollo. }\end{array}$ & $\begin{array}{l}\text { Los enfoques respecto al medio ambiente pueden, a veces, estar } \\
\text { disociados de las cuestiones relativas al desarrollo. }\end{array}$ \\
\hline $\begin{array}{l}\text { El desarrollo y el crecimiento van a } \\
\text { resolver los problemas ambientales. }\end{array}$ & $\begin{array}{l}\text { El desarrollo y el crecimiento podrían empeorar los problemas } \\
\text { ambientales y sociales. }\end{array}$ \\
\hline
\end{tabular}


Podemos confiar en las trasferencias de las ciencias ambientales $y$ tecnologías.

\begin{tabular}{|c|c|}
\hline $\begin{array}{l}\text { Los niños deben comprometerse con } \\
\text { el medio ambiente }\end{array}$ & $\begin{array}{l}\text { El desarrollo de los niños requiere ambientes apropiados. Los } \\
\text { niños pueden encontrar sus maneras de comprometerse en el } \\
\text { mundo. }\end{array}$ \\
\hline $\begin{array}{l}\text { Hasta ahora, los resultados son } \\
\text { insatisfactorios. Hay una urgencia. }\end{array}$ & $\begin{array}{l}\text { Algunos resultados son prometedores. Es necesario avanzar } \\
\text { enérgicamente pero con prudencia, rigor, discernimiento y } \\
\text { precaución. }\end{array}$ \\
\hline \multicolumn{2}{|r|}{ Desarrollo } \\
\hline $\begin{array}{l}\text { Las propuestas internacionales } \\
\text { destacan, en general, los siguientes } \\
\text { aspectos: }\end{array}$ & $\begin{array}{l}\text { Las propuestas internacionales omiten, general, los siguientes } \\
\text { aspectos: }\end{array}$ \\
\hline $\begin{array}{l}\text { La economía es un campo de fuerzas } \\
\text { autónomo, externo, de la sociedad, } \\
\text { que determina la relación entre } \\
\text { sociedad y el medio ambiente. }\end{array}$ & $\begin{array}{l}\text { La economía es parte de la esfera social, es un aspecto de la } \\
\text { realidad social: resulta de elecciones responsables. }\end{array}$ \\
\hline $\begin{array}{l}\text { El desarrollo es requisito, una } \\
\text { obligación, un destino. }\end{array}$ & $\begin{array}{l}\text { El desarrollo es una opción, una elección. El requisito es } \\
\text { reflexionar sobre la noción de desarrollo y justificar una } \\
\text { concepción particular. }\end{array}$ \\
\hline $\begin{array}{l}\text { El desarrollo es el crecimiento } \\
\text { económico. }\end{array}$ & $\begin{array}{l}\text { El desarrollo es el despliegue de todo el espectro de } \\
\text { potencialidades humanas en un contexto específico. }\end{array}$ \\
\hline $\begin{array}{l}\text { La pobreza es un problema clave, } \\
\text { la causa principal de los problemas } \\
\text { sociales y ambientales. }\end{array}$ & $\begin{array}{l}\text { La pobreza es el síntoma de formas de alienación más profundas. } \\
\text { La pobreza contemporánea está causada por la apropiación de } \\
\text { los recursos económicos y los abusos ambientales y sociales por } \\
\text { una minoría privilegiada. }\end{array}$ \\
\hline $\begin{array}{l}\text { El desarrollo es un asunto global para } \\
\text { la gestión mundial. }\end{array}$ & El desarrollo es un proyecto endógeno. \\
\hline El desarrollo es una solución & El desarrollo es un posible problema. \\
\hline $\begin{array}{l}\text { La importancia de la cooperación, la } \\
\text { solidaridad y la interdependencia para } \\
\text { lograr el desarrollo mundial. }\end{array}$ & $\begin{array}{l}\text { La importancia de la autonomía, la auto gestión, la confianza } \\
\text { en sí mismo, como bases de las verdaderas cooperación y } \\
\text { solidaridad. }\end{array}$ \\
\hline
\end{tabular}

Es necesario valorar los distintos enfoques sobre el medio ambiente, verlo no sólo como un objeto externo que debe investigarse y gestionarse. Los enfoques filosóficos, holísticos, experienciales, literarios o artísticos deberían considerarse. niños pueden encontrar sus maneras de comprometerse en el Algunos resultados son prometedores. Es necesario avanza enérgicamente pero con prudencia, rigor, discernimiento y precaución.

Tabla 2. Resultados de la concepción de educación, medio ambiente y desarrollo.

Sauvé (2007) dice que para algunos el DS es la última meta de la EA, de ahí el termino de Educación Ambiental "para" el Desarrollo Sustentable; para otros, el DS acompaña objetivos específicos que deben añadirse a los de la EA, por eso la expresión $E A$ " $y$ " desarrollo sustentable; y para otros, la EA es inherente a la educación para el desarrollo sustentable, por lo que el uso de ambos términos sería tautológico, como parece sugerir
María Novo (2009), con quien estamos de acuerdo, al considerar la "educación ambiental como una genuina educación para el desarrollo sostenible".

La expresión "educación ambiental para el desarrollo humano sustentable" (que integra la variable económica, las variables ecológicas y éticas asociadas con la calidad de vida y los derechos y deberes humanos) y su articulación "EA y Sustentabilidad" (que evitaría 
la apelación al desarrollo económico y su asociación con el ambientalismo Neoliberal) sería, según nuestro criterio, una acepción específica en la que lo importante sería la pluralidad teórica y metodológica, que no requeriría subvertir todo el campo disciplinar de la EA, y cuya respuesta no residiría en abandonar el término sustentable, sino en convertirlo pragmáticamente en lo imaginado (Le Grange, 2008) desde otras visiones o paradigmas más críticos, pero también emancipadores, equitativos y orientados hacia la justicia social del presente y del futuro de la humanidad (Meira, 2008). Sería entonces una EA de profundidad comprometida con el cambio social, procurando más y mejores condiciones de perdurabilidad en concordancia con la ética ecológica que precisa la construcción de un desarrollo humano (Caride, 2008).

Sauvé (2007) con algunas modificaciones de la propuesta Gilbert Rist (1996) presenta cuatro vías alternativas:

- Proseguir la vigilancia crítica respecto de la propuesta y la aplicación de "desarrollo sostenible".

- Estimular la imaginación política y económica de nuestras sociedades.

- Explorar y valorizar las cosmologías alternativas en el ámbito local y regional, las iniciativas de desarrollo social "más allá del desarrollo".

- Fomentar y mejorar en el ámbito internacional (debido a las interdependencias), las políticas de las organizaciones internacionales, contribuyendo con ellas.

La década de la EDS podría ser una oportunidad para reactivar las discusiones, incorporando nuevos enfoques, y actualizar las posturas de la EA. Los docentes tendrían que tener confianza suficiente para lidiar con la siempre cambiante información, rasgo característico de este campo, y enseñar de una manera que estimule la crítica, al tiempo que la comprensión del grado de compromiso que tenemos con el planeta, generando espacios de reflexión, el análisis y la acción social que conduzcan, por un lado, a la cooptación para sacar el mejor partido $\mathrm{y}$, por otro, generar resistencia, creatividad y búsqueda de alternativas, pero no tratando de unir "temas" sin más, sino tratando de construir un proyecto educativo coherente, fundado sobre una visión del mundo rigurosamente clarificada y enriquecida sin cesar, desde un carácter ético y político (sin politizarse) de la acción educativa.

La EA para el desarrollo humano sustentable convoca a que las propuestas curriculares se ajusten y se reformen no como algo que se adiciona sino que se debe integrar mediante un proceso de ambientalización curricular o de inclusión de la dimensión ambiental al currículo, de manera innovadora, global y asociada a todos los campos disciplinares de conocimiento, no a uno en concreto, impregnando todas las actividades de las instituciones escolares, para lo cual la formación permanente del profesorado es fundamental.

Si bien no existe consenso generalizado sobre los principios y metodologías a integrar en los procesos de ambientalización curricular y de selección de contenidos de enseñanza, consideramos que dependen necesariamente del contexto teórico desde donde se mueven las distintas corrientes de educación ambiental (Mora, 2007), y donde los planteamientos de la cartografía propuesta por Lucié Sauvé (2004) podrían ser de gran utilidad. 
A las universidades y facultades, en especial aquellas encargadas de la formación de docentes, se les convoca a ser coherentes con su articulación a la solución de los problemas planetarios, ambientalizando y haciendo flexibles sus currículos, bajo miradas inter y transdisciplinarias que hagan posible la formación de sus egresados para que sean capaces de asumir sus actuaciones con la responsabilidad que requiere una formación en EA para el Desarrollo Humano Sustentable; es por ello que el papel docente se transforma de dictar clases, al diseño de espacios de aprendizaje en un contexto de transición, hacer el salto, de una cultura de trabajo en el aislamiento en el aula de clase y de su individualismo, a la responsabilidad en el diseño curricular de forma colectiva, entre pares y su puesta en práctica respetando los principios formativos institucionales y del currículo de cada carrera (Mora, García y Mosquera, 2004).

\section{Las problemáticas ambientales locales: el caso educativo colombiano}

Desde la primera globalización iniciada en el siglo XV con la conquista europea, $y$ luego con la globalización de las ideologías economicistas marxistas y neoliberales, las problemáticas ambientales en Colombia han estado asociadas a problemas de crisis interna, de violencia y odio, presentándose en las últimas décadas una intensificación por su vínculo al narcotráfico como financiador de grupos de delincuencia organizada, guerrillas y paramilitarismo, que ha implicado la destrucción de los ecosistemas y la insostenibilidad general.

Esta situación reclama una tercera globalización, la de la complejidad e interdisciplinariedad (Carrizosa, 2003) para crear escenarios de consenso y de modelos de solución. Esta tercera globalización implicaría no sólo el plano político, sino su articulación en equilibrio con lo económico, ecológico y ético, para buscar la reconciliación en un proceso de cambio que requiere de la ayuda de los países que han sido corresponsales de la situación presente del país.

Carrizosa (2003) plantea que para construir una tercera globalización de la cultura compleja y solidaria, se requiere superar obstáculos como: la retórica (acerca del desarrollo sostenible), la corrupción (que hace prevalecer los intereses individuales sobre los sociales), la incoherencia (que lo disgrega todo), la inoportunidad (por los modelos de gestión inaplicables), la complejidad (del medio físico-biótico, y la diversidad del medio socio cultural crean condiciones de incertidumbre y riesgo), la ineficiencia, la discontinuidad (de los proyectos y actividades) y la falta de concreción (que impide el paso de las ideas a los hechos).

En Colombia, la Constitución Política de 1991 ha generado una normatividad que fomenta una educación para la cultura ambiental en todos los ámbitos educativos, se orienta a la protección del ambiente y el derecho a un ambiente sano al nivel de los otros derechos colectivos. El concepto de DS se introdujo con relación al manejo y aprovechamiento de los recursos naturales y, con la ley 99 de 1993 que creó el Sistema Nacional Ambiental, se incluye una definición específica de DS, que privilegia el crecimiento económico, como fin y no como medio. 
A partir de los planteamientos constitucionales se ha elaborado la Política Nacional de Educación Ambiental, (MMASINA, 2002) y en este mismo marco se formula el Decreto 1743 de 1994 (instrumento político fundamental para la Educación Ambiental en Colombia), a través del cual se institucionaliza el Proyecto de Educación Ambiental para todos los niveles de educación formal, se fijan criterios para la promoción de la EA no formal e informal y se establecen los mecanismos de coordinación entre el Ministerio de Educación Nacional y el Ministerio del Medio Ambiente para todo lo relacionado con el proceso de institucionalización de la EA.

Incluir la dimensión ambiental como un deber, sobre todo en los niveles educativos básico y medio, ha estado asociado a los Proyectos Ambientales Escolares (PRAES), como eje transversal en el marco de los Proyectos Educativos Institucionales PEI, que están vinculados a la solución de la problemática ambiental particular de una localidad o región (Torres, 1996); ello ha planteado retos en la formación inicial y permanente de los docentes, tanto de ciencias naturales como sociales, de las facultades de educación, desafíos que en muchos casos no han sido atendidos durante los procesos formativos que se ofrecen.

El sistemismo, la interdisciplina (abiertos a otras epistemologías y axiologías distintas del área ecológica o del área ética y moral), la gestión (en contacto con los organismos e instituciones encargadas de la gestión ambiental), la ciudadanía (formada en actitudes y valores que permitan construir ciudadanos éticos y responsables), y el énfasis en el trabajo de campo con sentido de pertenencia en lo local y regional, son los retos particulares en los procesos formativos de los docentes que trabajan en la EA y que muchas veces aparecen desintegrados o ausentes de las propuestas curriculares formativas.

Aunque existe una normatividad, el proceso a nuestro parecer, ha sido lento y todavía puede quedar el lastre, en muchas instituciones, de los procedimientos anteriores a la propuesta de los PRAES. La profesora Maritza Torres (2002) nos dice que la imagen del profesorado es la de un personaje al que "se le hacen encargos” a partir del envío de cartillas y folletos donde se le imponen campañas "del agua”, "del árbol”, "del suelo", "del reciclaje”, etc., sin que conozca la conceptualización histórica respecto del tema ni haya sido invitado a hacer parte del proceso de construcción o de sus propuestas educativas, y lo más grave, sin que corresponda a las necesidades derivadas del diagnóstico ambiental de las localidades o de las zonas donde se encuentra inmersa la institución escolar, por lo que tampoco hacen parte de la vida de la escuela.

Así, se pueden encontrar proyectos de reciclaje escolar en los que el problema ambiental prioritario no es el de los desechos sólidos o las huertas escolares y donde la prioridad ambiental de la localidad no es el manejo de los suelos. En casos extremos lo que se trabaja como "reciclaje" en los diferentes proyectos escolares, es apenas la selección y la clasificación de desechos, todo por la falta de un espíritu crítico y con visión futurista; el comportamiento de muchos docentes respecto del mejoramiento en la calidad de las relaciones sociedad-naturaleza-cultura, se puede esquematizar así: "si se están acabando las fuentes de 
agua, entonces, hay que sembrar árboles": de inmediato aparece el problema, aparece la solución "mágica" (Torres, 2002:104).

Por otro lado el MEN (2004), de la mano con el surgimiento, nacido de las recomendaciones de la EDS, de los Estándares Básicos de Competencias para la educación básica y media colombiana (que dictan las acciones de pensamiento y producción, en relación con las responsabilidades que se deben asumir cuando se conocen y valoran críticamente los descubrimientos y los avances de las ciencias), ha querido acercar las ciencias naturales a las ciencias sociales intentando promover una educación crítica y ética, tolerante con la diversidad y comprometida con el medio ambiente, constituyendo un puente para crear comunidades con lazos de solidaridad, sentido de pertenencia y responsabilidad frente a lo público y lo nacional.

Sin embargo, los procesos de formación inicial y permanente del profesorado para participar el en desarrollo de currículos y de prácticas pedagógicas y didácticas en el aula, parecen distar mucho de ir en consonancia con estas propuestas, por lo que nos preguntamos: ¿están los docentes preparados para los retos de integración del conocimiento, de la interdisciplinaridad y del sistemismo, asociado a la resolución de problemas ambientales en un marco de sustentabilidad? ¿Son las propuestas de formación de docentes, inicial y permanente, que ofrecen las facultades de educación pertinentes a estas demandas?

Aunque creemos que el profesorado en ejercicio no está preparado para los retos que la complejidad de las problemáticas ambientales demanda, al estar articuladas a la cultura institucional de aislamiento docente que impide la reflexión interdisciplinar del profesorado, también es claro que las propuestas de formación inicial y permanente del profesorado de las facultades de educación son muy pobres y no pertinentes. Sin embargo, responder a estas preguntas y a las conjeturas que planteamos, implica todo un proceso investigativo que escapa a las intenciones de este trabajo, por lo que sólo intentaremos reunir críticamente algunas fuentes para argumentar posibles procesos de cambio en los procesos formativos del profesorado de educación ambiental, iniciando con el planteamiento de las dificultades que parten de la falta de acuerdo sobre el conocimiento de la educación ambiental.

\section{Dificultades del campo educativo de la EA}

Por tradición, la mayoría de enfoques de EA en las instituciones escolares han estado separados de la gestión y del trabajo didáctico, por lo que no logran un lugar distinto del que su separación de estos dos factores les permite; Las actividades en EA tienen como único fin cumplir con exigencias normativas, pero sin trascender a respuestas efectivas de gestión o de aprendizajes en las aulas. Muchos consideran la EA como un campo históricamente inmaduro, indefinido (por su nacimiento, reciente en los años 70s del siglo XX), y altamente diverso, motivos que impiden la aceptación de la didáctica de la EA (ya que piensan que lo didáctico centraría los problemas de EA al aula escolar exclusivamente y alejaría la escuela de las actividades de participación en la gestión ambiental).

Otros han delimitado los campos de acción de la EA sólo a la gestión, negán- 
dose a aceptar por ejemplo, el periodismo ambiental como espacio de la EA, de igual manera, se confunde la participación de una EA formal con la de una no formal; pareciera que la publicidad ha permitido más avances en lo no formal, mientras que lo formal que estaría a cargo por ejemplo de la didáctica, está muchas veces desvinculado de la EA no formal y de la gestión ambiental; para otros, la EA formal tiene su contexto sólo en la educación básica y media y no en la educación superior, como se puede ver en ausencia de la ambientalización en sus currículos (Junyet et al, 2003; Mora, 2008).

Daniel Luzzi (2000) sostiene que la EA en las instituciones educativas formales se ha reducido, en la mayoría de los casos, a un tema más de los denominados "emergentes de la comunidad o temas transversales" y de paso, a un recetario dispuesto para todo tipo de inserción, desde las más pertinentes hasta las más arbitrarias e irreflexivas; bajo esta reclamación Luzzi no considera conveniente que la EA sea transversal a cada una de las áreas disciplinares, como la lengua, las matemáticas o la educación en valores, y sostiene que la EA es más que ello, una "infusión", pues obedece a una compleja dinámica histórica de la educación en diálogo con las concepciones del conocimiento, el aprendizaje, la enseñanza, la sociedad y el medio ambiente.

Luzzi entiende la EA como un eje natural de convergencia disciplinar, capaz de dar cuenta de la problematización de las diversas disciplinas, irradiándolas, transformándolas, y de la reorganización de las prácticas actuales de aprender a aprender la complejidad de la realidad, por lo que la EA reclama la producción de un saber ambiental que cuestione las distintas disciplinas, generando nuevos conocimientos, nuevas maneras de interpretación; además de la comprensión de la realidad, al replantearse la responsabilidad social y la complejidad del presente y futuro planetario. Así la dimensión ambiental, lejos de incorporarse transversalmente como un área de conocimiento más, pasa a constituirse en el centro de análisis de la cuestión educacional, interiorizada a través de un diálogo de saberes que sobrepasa el campo de la racionalidad científicotecnológica, construyéndose en relación con las condiciones sociales, culturales, los procesos productivos, etc.

Gutiérrez (2002) y García-Díaz (2004), sustentan que la EA atraviesa por una serie de problemas estructurales que determinan sus prácticas y que parecen no estar resueltos en el presente:

- La EA es un ámbito de conocimiento en el que no hay un paradigma unificador establecido, prevaleciendo la heterogeneidad, la controversia y las discrepancias que se reflejan en una gran confusión teórica y metodológica que no permite la formación de un cuerpo de conocimiento consensuado en una comunidad académica propia, lo que dificulta la investigación (mayoritariamente descriptiva).

- El modelo inicial de corte naturalista centrado en la comprensión del medio, un modelo predominante, ambientalista y positivista, que tiende a proteger el medio, y una visión emergente próxima a la sustentabilidad y al cambio social, han generado polaridades, por un lado hacia el cambio conceptual y el cambio de actitudes y valores, y por otro, dirigidas a la práctica, muchas veces sin una marco teórico de referencia, que degenera en visiones tecnicistas y activistas de la EA. 
- Hay muy pocos grupos de investigación, integrados interdisciplinarmente, dedicados a la EA, sumado a que la preocupación por ésta ha sido evidente en colectivos e instituciones ajenas al campo educativo, lo que supone graves carencias en sus procesos de formación.

- En la medida en que se integran cada vez más profesionales del área social, se ha ganado en la perspectiva crítica y de integración de la EA con la educación global, el desarrollo sostenible, la educación en valores, pero a su vez, la perspectiva ecológica ha perdido terreno en la formulación de los contenidos ambientales, en la medida en que los aspectos económicos, políticos, sociales, etc., aparecen como exigencia en los currículos.

- Insuficiente valoración de áreas como la sicología ambiental, la didáctica de las ciencias e incluso de la pedagogía.

- En la EA actual se da una paradoja, al tiempo que se rechaza la concepción positivista del mundo (ya que los discursos invitan a adoptar un pensamiento complejo y crítico) se admiten posiciones positivistas y conductistas respecto al modelo de aprendizaje. Se requiere abrir un debate sobre los momentos y fines más adecuados para sustentar las estrategias de intervención en modelos asociacionistas o en modelos constructivistas, pues esta confusión ha frenado el desarrollo de la EA.

- En el campo de la EA no hay un desarrollo adecuado del ámbito didáctico, apenas si hay discusión sobre la naturaleza epistemológica de los objetivos, contenidos, organización y secuenciación. Las revistas de prestigio internacional, igual que muchos de los investigadores reconocidos en EA, apenas si le dan importancia al ámbito didáctico de la EA.

- Aunque la tradición de la EA ha sido relevante en la formulación y organización de los contenidos escolares, no lo ha sido tanto en la relación de estos contenidos respecto de las estrategias didácticas de enseñanza que se pueden vincular, particularmente, con aquellas fundamentadas en los procesos constructivistas del aprendizaje del estudiantado, como la formación inicial y permanente del profesorado de EA.

- La mayoría de las actividades de EA han encontrado distintos obstáculos e inercias que impiden la eficacia de sus propuestas. Por ejemplo, Vilches y Gil (2003) afirman mediante tres razones que el profesorado ha cuestionado la efectividad de cualquier acción de EA:

a. La responsabilidad de la situación actual no recae en las personas sino en "el poder", es decir, en los políticos y, sobre todo, en el complejo financiero industrial transnacional.

b. Lo que puede hacer cada cual para mejorar la situación es irrelevante frente a las acciones de la gran industria.

c. Las acciones educativas son ineficaces y la mayoría de los ciudadanos mantienen comportamientos depredadores, sin atender a explicaciones y llamamientos.

\section{EA y currículos formativos}

De la misma forma que existen límites difusos entre disciplinas y saberes que participan en la resolución de problemas ambientales, el campo teórico en construcción de la EA se encuentra impregnado por distintas perspectivas de inclusión de lo ambiental en el currículo; muchos proponen una visión transdisciplinar articulada a temas transversales, otros, transformada en educación en valores para el desarrollo sostenible, sin embargo es posible encontrar tres perspectivas destacables:

- La educación global. Para Selby (1996) son cuatro las dimensiones interrelacionadas en la estructuración de una educación global: la dimensión espacial, la dimensión temporal, los temas globales, 
y (en el centro de las interacciones) el mundo interior (el Yo); estas dimensiones permitirían diseñar currículos que nos proyecten a una educación para el futuro que sustente mutuamente la persona y el planeta, al formarse una serie de conciencias de los estudiantes para pensar en forma sistémica: conciencia de perspectiva que permite reconocer que nuestras visiones de mundo no son compartidas universalmente; conciencia de la salud del planeta y de sus condicionamientos globales en torno a los derechos humanos; conciencia de la participación y de la preparación desde habilidades sociales y políticas para la toma de dediciones democráticas en los niveles glocales y conciencia y valoración de los procesos de aprendizaje continuo a lo largo de toda la vida.

A su vez Yus (1997) parte de una concepción de la realidad global, sistémica y compleja, planteando como ejes: la globalización de la cultura, la educación integral de las personas, la organización democrática de la escuela y el compromiso de la educación con la problemática socio-natural para un pensamiento solidario que permita afrontar los problemas y crisis del mundo actual y futuro. Este enfoque de educación global nace de propuestas fundamentadas en la transversalidad del currículo y de los temas transversales (entendidos como organizadores de contenidos interdisciplinarios, a manera de núcleos de interés educativo que no tienen una ubicación precisa espacio/temporal en el currículo y que carecen de una epistemología específica).

Sin embargo, este enfoque es criticado por la falta de un sistema conceptual de referencia que organice e integre los conocimientos (Porlán y Rivero, 1998), debido a que se presenta de manera individualizada, como un grupo de temas inconexos y optativos en los currículos. Una solución que ha planteado Yus
(1997) es transversalizar los transversales, globalizando la educación en un sistema de temas relacionados con la salud, el medio ambiente y la sociedad, los cuales incluirían la paz, la calidad de vida y la solidaridad; aunque en el fondo subsiste la imagen de que esta propuesta puede llevar al camino de la moralización y no al del pensamiento sistémico, autónomo y divergente.

- Los movimientos $C / T / S / A$, tendientes a la alfabetización en ciencia-tecnología y ambiente para todas las personas (que contribuyen en una cultura ciudadana, a la toma de decisiones razonadas y democráticas acerca de los problemas que enfrenta la humanidad, a la formación de espíritu crítico, y principalmente, al disfrute personal) (Acevedo y otros, 2003; Gil y Vilches, 2003; Cañal, 2004), tienen un carácter crítico respecto de la clásica visión positivista, esencialista y triunfalista de la ciencia y la tecnología, y un carácter interdisciplinar que se sitúa en la transformación del currículo de las ciencias (naturales/sociales) teniendo como marco de referencia básico para la determinación del conocimiento escolar, el conocimiento científico (la meta a alcanzar es la ciencia, aproximando las ideas de los estudiantes a las científicas), mientras la educación global y la transversalidad afectan todo el currículo escolar y las ciencias son un conocimiento más.

García-Díaz (2006) previene acerca de la tendencia pendular de este enfoque, pues se mueve entre dos reduccionismos: de los contenidos de la ecología -como ciencia compleja y como cosmovisión- (tanto de los sistemas naturales como de los humanos), y de los aspectos sociales, ideológicos y eticistas que ignoran la importancia de las ciencias de la naturaleza. Díaz argumenta que no se trata de adicionar factores nuevos a la naturaleza de las ciencias, sino de 
superar las concepciones mitificadas del trabajo científico como una actividad neutral, descontextualizada, ajena a intereses y conflictos, en la que es importante asumir posiciones críticas ante la racionalidad económica dominante; en fin, una educación de las ciencias que además de facilitar la construcción del mundo sea un instrumento para comprender y actuar en él.

- La perspectiva socio-crítica (Caride y Meira, 2001; Porlán, 2001; García-Díaz, 2004), tiene asiento en la articulación de las ciencias naturales, sociales y ambientales como la ecología, los saberes filosóficos y las ciencias psicopedagógicas y didácticas, para la trasformación de la escuela y la sociedad. Esta perspectiva discute con muchas de las visiones anteriores, aquellas que admiten que todos somos responsables de la crisis ambiental y social ignorando que la responsabilidad habría que buscarla en la naturaleza de las estructuras sociales y económicas dominantes, así como en las ideologías que las sustentan.

Este enfoque muestra el currículo global como integración de saberes complementarios que se ponen en juego en la solución de problemas escolares, en los que se hace fundamental trabajar conceptos metadisciplinares, así

“...la ciencia disciplinar no es el objeto último de la educación ni el referente exclusivo para la determinación del conocimiento escolar. Los problemas que se deberían trabajar en la escuela son los problemas relevantes para los ciudadanos, no los problemas científicos, de forma que no se trata de acercarse a lo social desde la ciencia, sino a la ciencia desde lo social", "el conocimiento escolar es una transición desde formas simples del pensamiento hacia otras más complejas", "el conocimiento metadisciplinar alude a conceptos como sistema, cambio, interacción o diversidad, a procedimientos propios del trabajo de problemas complejos y abiertos, y a valores relativos a una visión relativizadora, autónoma y solidaria del mundo".

Interpretando a García-Díaz (2004) se podría pensar que la integración debe cuidarse de no generar un nuevo reduccionismo simplificador al tratar de fusionar apresuradamente diversos campos en uno sólo, llámese educación global o educación para el desarrollo sostenible; lo importante, a la hora de formular contenidos de EA, es la complementariedad e integración entre lo general y lo específico y que además sean una construcción abierta, flexible y progresiva de problemas socio-ambientales, que funcione como eje articulador de los contenidos en un contexto cultural de lo científico-técnico y lo metadisciplinar (como marco de referencia en el diseño y programación de los diferentes niveles de complejidad de los contenidos).

\section{Retos para la formación de formadores}

Como ya se ha dicho, la situación de emergencia planetaria hace que la dimensión ambiental sea parte fundamental de los procesos formativos en todos los ámbitos educativos y parte central de las actividades del desarrollo profesional docente; sin embargo, "ambientalizar” los programas curriculares y los contenidos de enseñanza, requiere de un proceso de apertura de los paradigmas teóricos, las barreras institucionales $y$ los intereses disciplinarios, si se quiere apuntar a reformas que vayan más allá de la buena voluntad o de las declaraciones de papel. 
La universidad no puede educar en valores que no tiene ni practica, no puede pregonar la sustentabilidad, ni la inter y transdisciplinariedad, ni la multiculturabilidad, si ella no es sustentable, si no respeta la diferencia, si no desarrolla entre sus académicos una actitud inter y transdiciplinar. Es fundamental una nueva estructuración de las universidades que supere las clásicas formas de organización por facultades monóliticas, unidimensionales y de yuxtaposición de monodisciplinas encorsetadas rígidamente en compartimentos departamentales que no estimulan la interdisciplinariedad ni la flexibilidad.

Esta nueva estructuración debe cuestionar a los departamentos para la solución de problemas complejos de naturaleza ambiental; movilizándose hacia la creación de proyectos curriculares que convoquen distintos conocimientos y saberes provenientes de distintas facultades en un diálogo entre lo natural y lo social, estableciendo puentes entre distintas disciplinas, profesiones y oficios. Para esto se requiere un cambio de actitud del profesorado formador de formadores en ciencias, que supere la enseñanza de la historia de las ciencias naturales y la enseñanza de las monodisciplinas, y se interese por los problemas de las tecnociencias en la sociedad y los problemas globales ambientales (Mora, 2007; 2008).

Las reclamaciones formativas del profesorado no sólo se dan en el plano de la generalidad de lo ambiental, (que se sustentan en la idea de que si los docentes no entienden la crisis global y ambiental no pueden preparar a sus estudiantes para ella y para que sean ciudadanos del mundo), sino en opinio- nes que afirman que si no se integra al profesorado con el entendimiento, la sociedad del conocimiento (o sociedad del aprendizaje) y con las nuevas formas de la comunicación propias de la era digital, tampoco tendría una formación docente competente.

Cada vez hay un mayor consenso en torno a la idea de que las nuevas tecnologías de la información anuncian el fin de la enseñanza universitaria tal como la conocemos, pues experimentará un cambio hacia una comunidad académica virtual, es decir una comunidad en la que el profesorado aprende e intercambia ideas electrónicamente; así las nuevas tecnologías digitales señalan el inicio de un mundo nuevo, más dinámico e interactivo, con nuevos riesgos y desafíos, del mismo modo que la imprenta de Gutemberg marcó el inicio de la modernidad.

El aprendizaje se ha convertido en un hecho permanente que se manifiesta como respuesta a un mundo en constante cambio y competitividad, por ello requiere de una constante innovación en el campo productivo y personal. Esta exigencia hace que gran número de egresados reclamen una educación más allá del título universitario, dirigida a la consecución de competencias que permitan "reciclar" sus aprendizajes mediante educación postgradual y formación a lo largo de toda la vida, capaz de resolver problemas en diferentes situaciones e intensiones, desde diversas culturas e idiomas. En este contexto de retos educativos las instituciones y el profesorado están avocados a diseñar nuevos enfoques sobre la enseñanza, creando mejores entornos educativos, centrándose en el estudiante y no en el profesor. Así, "el mayor desafío con que deberán 
enfrentarse muchas universidades en la próxima década y los años siguientes consistirá en cambiar los entornos de aprendizaje" (Hanna, 2002).

En este escenario el aprendizaje remplaza la enseñanza de contenidos únicamente conceptuales, o por lo menos cambia su sentido, haciendo énfasis en capacidades de pensamiento de alto nivel, en la metacognición, en la comprensión, en la aplicación de inteligencias múltiples, en estrategias de aprendizaje cooperativo centradas en la resolución de problemas socialmente pertinentes que demandan contenidos conceptuales y procedimentales, en el uso de amplia gama de formas de evaluación y en la utilización de las TICs.

Estos requerimientos irían en otra dirección de la enseñanza tradicional basada principalmente en la clase magistral, también serían incompatibles en buena parte con la educación a distancia que se centra en la experiencia personal de individuos aislados y dependiente de un instructor (así hallan interacciones interpersonales mediante redes de comunicación y comunidades virtuales), reclamando la conexión entre estudiantes y docentes en forma de trabajo colaborativo en torno a problemas reales y de contexto; aprovechando el mundo de información disponible en bases de datos y en la red.

Articulando las ideas expresadas este documento se podría decir que nuevas formas de enseñanza, centradas en el aprendizaje y la resolución de problemas de carácter socio ambiental, demandan una epistemología sistémica para la construcción del conocimiento. Esto significa convertir de nuevo a la pedagogía y la didáctica en profesiones en las que hagamos de la docencia una misión social y una profesión creativa, en las que los docentes conozcan y se preocupen por su mundo a la vez que por su profesión, recuperando su estatus y dignidad como unos de los principales intelectuales de la sociedad y no que sigan siendo los técnicos e instrumentos de otras personas que les diseñan los currículos.

\section{Conclusión}

A lo largo de este documento se ha querido mostrar como la EA viene siendo avocada a un proceso de tensión en relación con la propuesta educativa conocida como Educación para el Desarrollo Sostenible, que debe ser tomada como una oportunidad más que como una amenaza a la continuidad del campo educativo de la EA, por lo que es necesario participar en espacios de reflexión académica frente a las demandas que genera el estado de crisis planetaria en que nos encontramos.

Las propuestas relacionadas con la trasversalidad de currículos globales, el enfoque CTSA para la alfabetización científica para todos y los currículos socio-críticos dirigidos a la transformación social, aparecen como propuestas importantes a tener en cuenta que demandan procesos formativos adecuados para el profesorado partícipe en ellas, en particular del profesorado formador de formadores, a quienes se les demandan procesos de desarrollo profesional pertinentes a las nuevas realidades, generando propuestas curriculares colectivas de formación de profesores (licenciados) donde la inclusión de la dimensión ambiental en dichos currículos sea el centro de las propuestas formativas. 


\section{Bibliografía}

Acevedo, José., Vázquez, Ángel., y Manassero, María. (2003). El movimiento Ciencia - Tecnología - Sociedad y la enseñanza de las ciencias. Obtenido el 20 de marzo de 2005, desde http:// www.campus-oei.org/salactsi/acevedo13.htm.

Ángel, Augusto. (1995). La fragilidad ambiental de la cultura. Editorial Universidad Nacional. Bogotá: Instituto de Estudios Ambientales.

Cañal, P. (2004). La alfabetización científica: ¿Necesidad o utopía? Cultura y Educación, 2004, 16 (3), 245-257.

Caride, José., Meira, Pablo. (2001). Educación ambiental y desarrollo humano. Barcelona: Ariel Educación.

Caride, José. (2008). El Complejo territorio de las relaciones educación-ambiente-desarrollo. En González-Gaudiano, Edgar J. (2008). Educación, medio ambiente y sustentabilidad. México: Siglo XXI - UANL, 73-92.

Carrizosa, Julio., (2003). Colombia de lo imaginario a lo complejo. Reflexiones y notas sobre Ambiente, Desarrollo y Paz. Bogotá: IDEA - UN.

Clarke, D. \& Hollingsworth, H. (2002). Elaborating a model of teacher professional growth. Teaching and Teacher Education. 18, 947-967.

Colucci-Gray, L., Giuseppe, E., y Gray, D. (2006). From scientific literacy to sustainability Literacy: An Ecological Framework for Education. Science Education. 90, 227-252.

Fernández Buey, Francisco. (2007) ¿Es el decrecimiento una utopía realizable? Papeles, No. 100, 53-61.

Fundación Terra (2008). Acreixement. Perspectiva Ambiental, No. 44

García, Rolando. (2006). Sistemas complejos. Conceptos, método y fundamenta- ción epistemológica de la investigación interdisciplinaria. Barcelona: Gedisa.

Garciandía, José A. (2005). Pensar sistémico. Bogotá: Pontificia Universidad Javeriana.

García-Díaz, Eduardo. (1998). Hacia una teoría alternativa sobre los contenidos escolares. Sevilla: Diada Editora.

García-Díaz, Eduardo. (2000). Educación ambiental y ambientalización del currículo. En Perales, F.J., y Cañal de León, P. (Comp.), (2000). Didáctica de las ciencias experimentales. Madrid: Marfil. 585-613.

García-Díaz, Eduardo. (2004). Educación ambiental, constructivismo y complejidad. Sevilla: Diada Editora.

García-Díaz, Eduardo. (2006). Educación ambiental y alfabetización científica: argumentos para el debate. Investigación en la Escuela, 2006, 60, 7-19.

Gell-Mann, M. (2003). El quark y el jaguar. Aventuras en lo simple y lo complejo. Barcelona: Tusquets.

González-Gaudiano, Edgar J. (2006, Julio 3 y 4). Environmental Education: a field in tension or in transition? Environmental Education Research, 12, 291-300.

González-Gaudiano, Edgar J. (2008). Configuración y significado: educación para el desarrollo sustentable. En González-Gaudiano, Edgar J. (Coord.) (2008). Educación, medio ambiente y sustentabilidad. México: Siglo XXI UANL, 213-227.

Gutiérrez, José. (2002). Grados de libertad y enfoques autóctonos de la investigación en educación ambiental. Investigación en la Escuela, No. 46, 27-39.

Hanna, Donald E. (Ed.) (2002). La enseñanza universitaria en la era digital. Barcelona: OCTAEDRO - UAB. 
Irwin, Ruth. (2008). "Postneoliberalismo": de la educación ambiental a la educación para la sustentabilidad. En González-Gaudiano, Edgar J. (Coord.) (2008). Educación, medio ambiente y sustentabilidad. México: Siglo XXI UANL, 176-212.

Junyent, Mercé., Geli Anna., y Arbat, Eva. (2003). Ambientalización curricular de los estudios superiores. Dos procesos de caracterización de la ambientalización curricular de los estudios universitarios. Girona: RED ACES - alfa.

Kerschner, Christian. (2008). Economía en estado estacionario versus decrecimiento económico: ¿opuestos o complementarios? Ecología política No. 5. Barcelona: Icaria editorial, desde www.ecologiapolitica.info. Recuperado: 02 de octubre de 2009.

Latouche, Serge. (2009). Pequeño tratado del decrecimiento sereno. Barcelona: Icaria Editorial.

Lazlo, Ervin. (2009). El cambio cuántico. ¿Cómo el nuevo paradigma científico puede transformar la sociedad? Barcelona: Editorial Kairós.

Leal F. Walter. (2009). La educación para la sostenibilidad: iniciativas internacionales. Revista de Educación, número extraordinario 2009, 263-277.

Leakey, R. y Lewin, R. (1997). La sexta extinción. El futuro de la vida y de la humanidad. Barcelona: Tusquets Editores.

Leff, Enrique. (Coord.) (2000). La Complejidad Ambiental. México: Siglo XXI Editores, 7-53.

Leff, Enrique. (2002). Saber ambiental. Sustentabilidad, racionalidad, complejidad, poder. México: Siglo XXI Editores-PNUMA.
Leff, Enrique. (2008). Decrecimiento o desconstrucción de la economía: hacia un mundo sustentable. Revista Polis. Vol. 7, No. 21, 81-90. Universidad Bolivariana de Chile.

Le Grange, Lesly. (2008). Hacia un lenguaje de probabilidad para la educación y para el desarrollo sustentable en Sudáfrica. En: González-Gaudiano, Edgar J. (2008). Educación, medio Ambiente y sustentabilidad. México: Siglo XXI UANL, 149-164.

Linz, Manfred., Riechmann, Jorge. y Sempere, Joaquim. (2007). Vivir (bien) con menos. Sobre suficiencia y sostenibilidad. Barcelona: Icaria.

López, Cerezo, J.A. y Luján, J.L. (1998). Filosofía de la Tecnología. Teorema Revista internacional de Filosofía. Obtenido desde <http://www.campusoei.org/salactsi/teorema00.htm> Tecnos. Vol. XVII/3, 1998.

Lukman, Rebeca. y Glavic, Peter. (2007). ¿What are the key elements of a sustainable university? Clean Techn Environ Policy. 2007 (9), 103-114.

Lujan, J.L. y Echeverría, J. (2004). Gobernar los riesgos. Ciencia y valores en la sociedad del riesgo. Madrid: OEI Biblioteca Nueva.

Luzzi, Daniel (2000). La "ambientalización” de la educación formal. Un diálogo abierto en la complejidad del campo educativo. En Leff, Enrique (Coord.) (2000). La complejidad ambiental. México: Siglo XXI Editores, pp. 158 - 192.

Martinez Alier, Joan. (2008). Decrecimiento sostenible-sustainable degrowth. First international conference on economic degrowth for ecological sustainability and social equity. Paris, pp. 37 - 41. Obtenido desde http:// events.it-sudparis.eu/degrowthconfe- 
rence/en/appel/Degrowth\%20Conference\%20-\%20Proceedings.pdf

MMA. Ministerio del Medio Ambiente, y Ministerio de Educación Nacional. (2002). Política Nacional de Educación Ambiental SINA. Bogotá, D.C.

Meira, Pablo. (2008). Crisis ambiental y globalización: una lectura para educadores ambientales en un mundo insostenible. En González-Gaudiano, Edgar J. (2008). Educación, medio ambiente y sustentabilidad. México: Siglo XXI - UANL, 53-72.

MEN. (2004). Estándares básicos de competencias en ciencias naturales y ciencias sociales. Formar en ciencias: el desafío. Lo que necesitamos saber y saber hacer. Serie Guías No 7. Bogotá: MEN.

Mora, William., García, Álvaro., y Mosquera, Carlos J. (2004). Estrategias para el desarrollo profesional en el campo pedagógico y didáctico del profesorado de ciencias experimentales y tecnologías a nivel universitario. En ICE- Universidad de Deusto (2004). Pedagogía Universitaria: hacia un espacio de aprendizaje compartido. III Simposio Iberoamericano de Docencia Universitaria. Vol. II, 1563-1580.

Mora, William M. (2007). Respuesta de la universidad a los problemas socioambientales: la ambientalización del currículo en la educación superior. Revista Investigación en la Escuela. 2007. 63 (3), 65-76.

Mora, William M. (2008). Inclusión de la dimensión ambiental en la docencia de la Facultad de Medio Ambiente y Recursos Naturales. Universidad Distrital Francisco José de Caldas. (55-67). En Bermúdez, Olga (Comp.), Memorias de los Foros Ambientales 2006-2007. Red temática de educación ambiental. Bogotá: IDEA-UN.
Morín, Edgar. (2000). Introducción al pensamiento complejo. Barcelona: Gedisa Editorial.

Morín, Edgar. (2001). Los siete saberes necesarios para la educación del futuro. Bogotá: UNESCO - Editorial Magisterio.

Morín, Edgar. y Hulot, Nicolás. (2008). El Año I de la era ecológica. La Tierra que depende del hombre que depende de la Tierra. Barcelona: Paidós.

Novo, María. (2003). La Educación ambiental. Bases éticas, conceptuales y metodológicas. Madrid: Editorial Universitas.

Novo, María. (2009). La Educación ambiental una genuina educación para el desarrollo sostenible. Revista de Educación, número extraordinario 2009, 195-217.

Pastor, Jaime. (2009). Ecosocialismo y "decrecimiento ¿cómo salir del imaginario dominante?". Economía. 6 (53). También publicado en: Revista Libre Pensamiento, No. 61.

Porlán, R. y Rivero, A. (1998). El conocimiento de los profesores. Una propuesta formativa en el área de ciencias. Serie Fundamentos No. 8. Sevilla: Díada Editora.

Porlán, R., Martín del Pozo, Martín., y Rivero, A. (2001). La relación teoríapráctica en la formación permanente del profesorado. Serie Fundamentos No. 16. Sevilla: Díada Editora.

Ridoux, Nicolás. (2009). Menos es más. Introducción a la filosofía del decrecimiento. Barcelona: Los Libros del Lince.

Riechmann, Jorge. (2006). Biomímesis. Ensayos sobre imitación de la naturaleza. Ecosocialismo y autocontención. Madrid: Los Libros de la Catarata. 
Robottom, Ian. (2008). La educación ambiental Re-etiquetada: ¿es la educación para el desarrollo sustentable algo más que un mero eslogan? En González-Gaudiano., Edgar J. (Coord.) (2008). Educación, medio ambiente y sustentabilidad. México: Siglo XXIUANL, 165-175.

Sauvé, Lucie. (2004). “Uma cartografia das correntes em educação ambiental”. En Sato, M. y Carvalho, I. (Coord.) Educação Ambiental: pesquisa e desafios. Porto Alegre: Artmed, 17-44. (Una cartografía de corrientes en educación ambiental). Obtenido el 11 de junio de 2009, desde http://www.scribd. com/doc/13011956/Cartografia-deCorrientes-de-Educacion-Ambiental.

Sauvé, Lucie. (2006). La educación ambiental y la globalización: desafíos curriculares y pedagógicos. Revista Iberoamericana de Educación, No. 41, 83-101.
Sauvé, Lucie. (2007). L'équivoque du développement durable. Chemin de traverse, No. 4, 31-47.

Torres, Maritza. (1996). La dimensión ambiental: un reto para la educación de la nueva sociedad. Bogotá: MEN.

Torres, Maritza. (2002). La educación ambiental en Colombia: un proceso construido a la luz de una mirada investigativa. En Miñana, Carlos. (Ed.) (2002). Interdisciplinariedad y currículo. Memorias del V Seminario Internacional. (Junio 19-23 de 2000) Bogotá: UN-RED.

Selby, D. (1996). Educación global: hacia una irreductible perspectiva global en la escuela. AULA de Innovación Educativa, 51, 25-30.

Vilches, Amparo. y Gil, Daniel. (2003). Construyamos un futuro sostenible. Diálogos de supervivencia. Madrid: OEI - Cambridge.

Yus, R. (1997). Hacia una educación global desde la transversalidad. Madrid: ANAYA S.A. 